\title{
Methods of Recycling, Properties and Applications of Recycled Thermoplastic Polymers
}

\author{
Mădălina Elena Grigore 1,2, \\ 1 Department of Polymers, National Research \& Development Institute for Chemistry \& \\ Petrochemistry (ICECHIM), Bucharest 060021, Romania \\ 2 Faculty of Engineering in Foreign Languages, University Politehnica of Bucharest, \\ 313 Independenţei Avenue, Sector 6, Bucharest 060042, Romania \\ Academic Editor: Michele Rosano \\ Received: 21 October 2017; Accepted: 27 November 2017; Published: 28 November 2017
}

\begin{abstract}
This study aims to provide an updated survey of the main thermoplastic polymers in order to obtain recyclable materials for various industrial and indoor applications. The synthesis approach significantly impacts the properties of such materials and these properties in turn have a significant impact on their applications. Due to the ideal properties of the thermoplastic polymers such as corrosion resistance, low density or user-friendly design, the production of plastics has increased markedly over the last 60 years, becoming more used than aluminum or other metals. Also, recycling is one of the most important actions currently available to reduce these impacts and represents one of the most dynamic areas in the plastics industry today.
\end{abstract}

Keywords: plastics recycling; chemical recycling; environmental impacts; energy recovery

\section{Introduction}

Polymeric materials can be classified as thermosets and thermoplastics. Thermoset polymers refer to the irreversible polymerization and this type of polymer is cured by chemical reaction or heat and becomes infusible and insoluble material. Thermoplastics are made up of linear molecular chains and this polymer softens on heating and hardens when cooled [1-6].

Thermoplastic polymers are represented by a large range of plastic materials. There are three types of thermoplastic polymers:

- Crystalline thermoplastics, usually translucent with molecular chains which present a regular arrangement. Compared to other types, these polymers have more mechanical impact resistance. Examples of this type of polymers are polypropylene (PP), low-density polyethylene (LDPE), and high-density polyethylene (HDPE).

- Amorphous thermoplastics, usually transparent with the molecules arranged randomly. Examples of this type of polymers are poly vinyl chloride (PVC), polymethylmethacrylate (PMMA), polycarbonate (PC), polystyrene (PS), and acrylonitrilebutadiene styrene (ABS).

- Semi-crystalline polymers present combined properties of crystalline polymers and amorphous polymers. The representative polymers of this group are polyester polybutylene terephthalate (PBT) and polyamide Imide (PAI) [1,7-10].

These polymers present unique properties (physical, thermal and electrical) that make them suitable for many applications. The injection modeling process is the main technique of polymer processing which allows the fabrication of different kinds of parts, such as the computer mouse [11-15].

These plastic materials can be modeled into a variety of products for a wide range of applications due to the fact that thermoplastic polymers are inexpensive, lightweight and durable. In the last 
decades, the production of plastics has increased significantly causing a big problem in the whole world regarding the discarded end-of-life plastics which are accumulated as debris in landfills and in natural habitats worldwide and by the management methods related to constantly growing resources of plastics. In the last years, the problem of recycled plastics was attempted to be solved by several methods (such as mechanical recycling or chemical recycling) leading to products ready to be used in determined conditions, in the most economic, ecological and rational way [16-23]. The purpose of this review is to present the advantages and disadvantages of thermoplastic polymers used in industrial applications, the processes used in the recycling and perspectives for a green bio-industry.

\section{Recycled Thermoplastic Polymers}

Due to the ideal properties of the thermoplastic polymers such as corrosion resistance, low density, high strength, and user-friendly design, plastic usage has become much higher than the usage of aluminum or other metals. For example, density is a very important parameter because it reveals information about the intrinsic strength of the construction that is supposed to be created, as in the case of flax reinforcement when PP and LDPE are the best choices (because of their low density) since its purpose is to produce a composite that is as light as possible. The glass transition temperature $(\mathrm{Tg})$ is another characteristic that is very important when studying polymer mechanical properties, because the flexibility of amorphous polymers is reduced drastically when they are cooled below $\mathrm{Tg}$. At these temperatures, there are no dimensional changes or segmental motion in the polymer. Also, the mechanical properties are very important in the case of thermoplastic polymers, mostly the tensile strength (important for their performance under stress) and tensile modulus (the resistance of polymers to elastic deformation) [12,24-31]. The main thermoplastic polymers and their properties are presented in Table 1.

Table 1. The properties of various polymers [32].

\begin{tabular}{llcccccc}
\hline \multirow{2}{*}{ Properties } & \multirow{2}{*}{ Limits } & PP & LDPE & HDPE & PC & PBT & PAI \\
& & 0.920 & 0.925 & 1.000 & 1.24 & 1.35 & 1.45 \\
\multirow{2}{*}{$\rho\left(\mathrm{g} / \mathrm{cm}^{3}\right)$} & Upper & 0.899 & 0.910 & 0.941 & 1.19 & 1.23 & 1.38 \\
\hline \multirow{2}{*}{$\mathrm{Tg}$} & Lower & -10 & -125 & -100 & 150 & 45 & 290 \\
& Upper & -23 & - & -133 & 140.5 & 20 & 244 \\
\hline \multirow{2}{*}{$\sigma_{\max }(\mathrm{MPa})$} & Lower & 41.4 & 78.6 & 38 & 72 & 55.9 & 192 \\
& Upper & 26 & 4 & 14.5 & 53 & 51.8 & 90 \\
\multirow{2}{*}{$E(\mathrm{GPa})$} & Lower & 1.776 & 0.38 & 1.490 & 3 & 2.37 & 4.4 \\
& Upper & 0.95 & 0.055 & 0.413 & 2.3 & - & 2.8 \\
\hline
\end{tabular}

Also, the plastic manufacturing cost is lower due to its simple mass production (Figure 1). The main reasons which make the thermoplastic polymers used in various applications are:

- The thermoplastic polymers can be processed by several methods leading to various kinds of plastic products;

- They are used for a specific application several compounding, operating condition, additives, fillers, and reinforcements;

- Several manufacturing systems are used at this moment to produce plastic items with the lowest cost range [33-35].

The recycling and incineration are the usual aspects of recovery methods in the case of thermoplastic polymers. The incineration presents some problems like the production of toxic gases and the residue ash which contains lead and cadmium. The recycling presents advantages such as reduction of environmental problems and saving both material and energy [33,35,36].

$$
\text { Collection } \rightarrow \text { Separation } \rightarrow \text { Manufacturing } \rightarrow \text { Marketing }
$$

Figure 1. The steps involved in thermoplastic polymers recycling. 
The plastic can be degraded in the environment by four mechanisms: photodegradation, thermo-oxidative degradation, hydrolytic degradation, and biodegradation by microorganisms. The natural degradation of plastic begins with photodegradation due to the UV light from the sun which provides the activation energy required to initiate the incorporation of oxygen atoms into the polymer, leading to thermo-oxidative degradation. In this step, the plastic becomes brittle and its fracturing into smaller pieces until the polymer chains reach sufficiently low molecular weight to be metabolized by microorganisms. The microorganisms convert the carbon of the polymer chains to carbon dioxide or incorporate it into biomolecules, but this process will take at least 50 years [36]. So, a solution to these problems will be the recycling, because most commodity plastics are relatively stable, making monomer recovery poor.

\subsection{Primary Recycling}

The most popular process is represented by the primary recycling due to their simplicity and low cost. This process refers to the reuse of products in their original structure. The disadvantage of this process is represented by the existence of a limit on the number of cycles for each material $[18,36,37]$.

\subsection{Secondary Recycling or Mechanical Recycling}

In this process, only the thermoplastic polymers can be used, because they can be re-melted and reprocessed into end products. The mechanical recycling does not involve the alteration of the polymer during the process.

This process is represented by a physical method, in which the plastic wastes will be formed by cutting, shredding or washing into granulates, flakes or pellets of appropriate quality for manufacturing, and then melted to make the new product by extrusion. Also, the reprocessed material can be blended with virgin material to obtain superior results. After the plastic is sorted, cleaned, dried and then directly processed into end products, the quantity of the waste plastic will be dramatically reduced (Figure 2). The disadvantages of this method refer to the heterogeneity of the solid waste and the deterioration of product's properties in each cycle which occurs due to the low molecular weight of the recycled resin. It happens because of chain-scission reactions caused by the presence of water and traces acidic impurities and to avoid lowering molecular weight intensive drying is recommended, the use of chain extender compounds or reprocessing with vacuum degassing. Also, this method is relatively inexpensive but needs substantial initial investment [18,36].

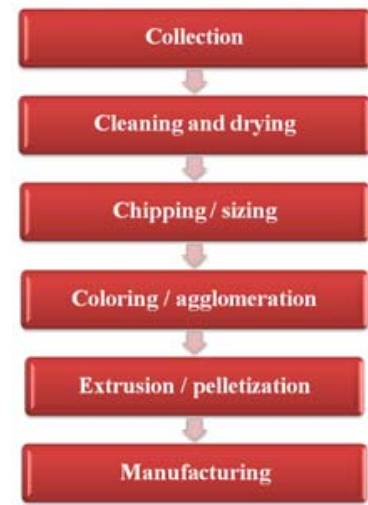

Figure 2. The steps involved in mechanical recycling.

\subsection{Feedstock or Chemical Recycling}

This process can be used with mechanical recycling as a complementation. Chemical recycling is defined as the process in which polymers are chemically converted to monomers or partially depolymerized to oligomers through a chemical reaction (a change occurs to the chemical structure of 
the polymer). The resulted monomers can be used for new polymerizations to reproduce the original or a related polymeric product. This method is able to transform the plastic material into smaller molecules, suitable for use as feedstock material starting with monomers, oligomers, or mixtures of other hydrocarbon compounds [36,38].

The chemical reactions used for decomposition of polymers into monomers are:

- Hydrogenation

- Glycolysis

- Gasification

- Hydrolysis

- Pyrolysis

- Methanolysis

- Chemical depolymerization

- Thermal cracking

- Catalytic cracking and reforming

- Photodegradation

- Ultrasound degradation

- Degradation in microwave reactor.

The chemical recycling is not fully developed and for this reason, only a few companies are working on it because this method needs a lot of investment and expert personnel. At this moment, numerous methods are under investigation; for example, the gasification and pyrolysis method is under extensive research to establish the suitable conditions, and the processes that have reached commercial maturity at this moment are glycolysis and methanolysis [36,39-41].

For example, PET (polyethylene terephthalate) can be cleaved by some reagents, like water (hydrolysis), acids (acidolysis), glycols (glycolysis) or alcohols (alcoholysis). According to the reagent used, different products are obtained.

Hydrolysis is a recycling method that involves a reaction of PET with water in an acid, alkaline or neutral environment, leading to total depolymerization into its monomers. The disadvantages of the hydrolysis method are represented by the high temperatures (between 200 and $250{ }^{\circ} \mathrm{C}$ ), by pressures (between 1.4 and $2 \mathrm{MPa}$ ) and by the long time needed to complete depolymerization. This method is not widely used, because of the high cost. Hydrolysis of PET flakes can be carried out by:

- Alkaline hydrolysis, which uses an aqueous alkaline solution of $\mathrm{NaOH}$ or $\mathrm{KOH}$, of a concentration of 4-20 wt \%. In a study, PET from post-consumer soft-drink bottles was cut into small pieces and then subjected to alkaline hydrolysis. After that, an autoclave was used; the temperature ranged from $120-200{ }^{\circ} \mathrm{C}$ with aqueous $\mathrm{NaOH}$ solutions and at $110-120^{\circ} \mathrm{C}$ with a nonaqueous solution of $\mathrm{KOH}$ in methyl cellosolve. Sulfuric acid was used to separate terephthalic acid (TPA) of high purity. It was reported that it was obtained about $2 \%$ admixture of isophthalic acid together with the pure $98 \%$ TPA and the activation energy calculated was $99 \mathrm{~kJ} / \mathrm{mol}$ [42]. Also, it was demonstrated by alkaline hydrolysis the possibility of simultaneously recycling PET and PVC from PVC-coated woven fabrics [43].

- Acid hydrolysis used concentrated sulfuric acid and also other mineral acids like nitric or phosphoric acid. In several studies, it was reported that the depolymerization of PET powder from waste bottles using nitric acid was carried out at temperatures between 70 and $100{ }^{\circ} \mathrm{C}[44,45]$. Also, it was reported the hydrolysis of PET using sulfuric acid (96 wt \%) at room temperature (30 $\left.{ }^{\circ} \mathrm{C}\right)$ [46].

- Neutral hydrolysis, using hot water or steam, high-pressure autoclaves at temperatures between 200 and $300^{\circ} \mathrm{C}$ and pressures of $1-4 \mathrm{MPa}$. It was reported that this method is more effective at temperatures higher than $245^{\circ} \mathrm{C}$, with complete depolymerization taking place at $275^{\circ} \mathrm{C}$ and its TPA yield being usually above $95 \%$ [42]. 
Of all these methods of hydrolysis, the neutral hydrolysis gets an increased interest because it is considered more environmentally friendly, but this method presents a main disadvantage namely that all mechanical impurities present in PET are left in the TPA, thus the product can be considered of lower purity than the product of acid or alkaline hydrolysis [41,42,47].

Chemical recycling of PET by glycolysis involves ethylene glycol insertion into PET chains to give bis(hydroxyethyl) terephthalate (BHET), which is a substrate for PET synthesis and other oligomers [41,48,49]. In a study, it was used for PET glycolysis several ionic liquids and basic ionic liquids as catalysts and it was observed that the basic ionic liquid, 1-butyl-3-methylimidazolium hydroxyl ([Bmim]OH), exhibits higher catalytic activity for PET glycolysis, compared with 1-butyl-3-methylimidazolium bicarbonate $\left([\mathrm{Bmim}] \mathrm{HCO}_{3}\right)$, 1-butyl-3-methylimidazolium chloride $([\mathrm{Bmim}] \mathrm{Cl})$ and 1-butyl-3-methylimidazolium bromide ([Bmim] Br) [50]. In another study, it was found that the purification process of the products in the glycolysis catalyzed by ionic liquids was simpler than that catalyzed by traditional compounds (metal acetate) [51]. Also, Pardal, F. and G. Tersac reported that the reactivity order of different glycols varies according to the conditions of temperature and catalysis. The global reactivity depends on the chemical reactivity of the glycol and on its physicochemical properties such as the polarity of the reaction mixture and ability to solvate the solid polyesters [52].

Chemical recycling of PET by methanolysis involves PET degradation by methanol at temperatures between 180 and $280^{\circ} \mathrm{C}$ and pressures from 2 to $4 \mathrm{MPa}$ with the main products being dimethyl terephthalate (DMT) and ethylene glycol (EG). Yang, Y. and co-workers reported that the optimal depolymerization conditions refers to the temperature between 260 and $270{ }^{\circ} \mathrm{C}$, the pressure of 9.0-11.0 MPa and the weight ratio (methanol to PET) from 6 to 8 [53]. After the main products are obtained, the DMT is purified by distillation to remove all of the physical contaminants and then it can be reused to produce PET [41,54]. Also, Kurokawa H and co-workers have reported that the rate of methanolysis strongly depends on the solubility of PET [55].

Polymers like PET produce mainly the monomers from which they have been produced. In comparison, polyolefins cannot be degraded with simple chemicals to their monomers due to the random scission of the $\mathrm{C}-\mathrm{C}$ bonds. Polyolefin are a major group of thermoplastics used throughout the world in applications such as toys, containers, bags, film, battery cases, and electrical components [56].

Chemical recycling uses a chemical process like pyrolysis which refers to the degradation of the polymeric materials by heating in the absence of oxygen. In a study, it was demonstrated that the oil and gaseous fractions recovered by pyrolysis of PP presented an aliphatic composition with a great potential to be recycled back into the petrochemical industry as a feedstock for the production of new plastics [39]. Achilias, D. and co-workers studied the recycling of LDPE, HDPE and PP by both a dissolution/reprecipitation technique (mechanical recycling) and pyrolysis (chemical/feedstock recycling). It was observed that mechanical recycling leads to high recovery of pure polymer with the disadvantage of using large amounts of organic solvents, while chemical recycling resulted to be the most promising technique. In the case of pyrolysis, a higher decomposition in PP, followed by LDPE and finally HDPE, was observed and also it was reported that the less crystalline or more branched polymers are less stable in thermal degradation [57].

The degradation of PS in various supercritical solvents (benzene, toluene, ethylbenzene) at 310-370 ${ }^{\circ} \mathrm{C}$ and 6.0 MPa pressure was studied. It was reported that PS had been successfully depolymerized; toluene was more effective than other solvents for the recovery of styrene from PS. Also, the highest yield of styrene was obtained from PS in toluene at $360^{\circ} \mathrm{C}$ for $20 \mathrm{~min}$ [58].

\subsection{Energy Recovery or Quaternary Recycling}

This method refers to the recovery of the plastic's energy content. The most effective way to reduce the volume of organic materials which involves the recovery of energy is represented by incineration. This method is a good solution because it generates considerable energy from polymers, but it's not ecologically acceptable because of the health risk from airborne toxic substances, for example, 
dioxins (in the case of heavy metals, chlorine-containing polymers, toxic carbon, and oxygen-based free radicals).

Among the above recycling techniques, the only one acceptable according to the principles of sustainable development is chemical recycling, because this method leads to the formation of the monomers from which the polymer is made [36,41,59-61]. Also, the advantages and challenges of the techniques are presented in Table 2.

Table 2. Summary of discussed techniques for recycling.

\begin{tabular}{lllc}
\hline \multicolumn{1}{c}{ Technique } & \multicolumn{1}{c}{ Advantages } & \multicolumn{1}{c}{ Challenges } & References \\
\hline Mechanical recycling & $\begin{array}{l}\text { Cost-effective, efficiency, } \\
\text { well-known }\end{array}$ & $\begin{array}{l}\text { Deterioration of product's } \\
\text { properties, pre-treatment }\end{array}$ & {$[18,62]$} \\
\hline Chemical recycling & $\begin{array}{l}\text { Operational for PET, } \\
\text { simple technology }\end{array}$ & $\begin{array}{l}\text { Mainly limited to } \\
\text { condensation polymers }\end{array}$ & {$[41,57,62]$} \\
\hline Energy recovery & $\begin{array}{l}\text { Generates considerable } \\
\text { energy from polymers }\end{array}$ & Not ecologically acceptable & {$[36,59]$} \\
\hline
\end{tabular}

\section{Applications of Recycled Thermoplastic Polymers}

Numerous waste materials are generated from manufacturing processes or municipal solid wastes every year. Due to the fact that solid waste management represents a big problem to the world, the waste utilization has become an attractive alternative to disposal. In 2012, according to the European Association of Plastics Recycling and Recovery (EPRO), $5.4 \mathrm{~m}$ tonnes were recycled, 34.7\%, of all the plastic packaging waste $[63,64]$. One such waste is plastic, which is currently used in various applications presented in Table 3.

Table 3. Applications of recycled plastics.

\begin{tabular}{cclc}
\hline Plastic & $\begin{array}{c}\text { Product Identification } \\
\text { Code (SPI) }\end{array}$ & \multicolumn{1}{c}{ Applications } & References \\
\hline PET & PETE & $\begin{array}{l}\text { Drink bottles, detergent bottles, clear film for } \\
\text { packaging, carpet fibers }\end{array}$ & {$[64]$} \\
\hline PVC & V & $\begin{array}{l}\text { Packaging for food, textile, medical materials, } \\
\text { drink bottles }\end{array}$ & {$[65]$} \\
\hline HDPE & HDPE & $\begin{array}{l}\text { Detergent bottles, mobile components, } \\
\text { agricultural pipes, compost bins, pallets, toys }\end{array}$ & {$[56,64]$} \\
\hline PP & PP & Compost bins, kerbside recycling crates & {$[18,64]$} \\
\hline PS & PS & Disposable cutlery & {$[66]$} \\
\hline LDPE & LDPE & Bottle, plastic tubes, food packaging & {$[56,67]$} \\
\hline Others * & OTHER & Containers & {$[68]$} \\
\hline
\end{tabular}

* Other plastics, including polylactic acid, acrylonitrile butadiene styrene, nylon and polycarbonate.

\subsection{Recycled Polymers for Food Industry}

The big problem with these recycled polymers refers to the possibility of contamination of virgin material and from contamination during the previous use of packaging and during production processes. The contamination of these materials may be of a chemical or microbiological nature [16]. Also, the Food and Drug Administration (FDA) has announced that their concerns with the use of recycled plastic materials in food-contact are related to:

- contaminants found in the post-consumer material which may appear in the final food-contact product made from the recycled material;

- recycled post-consumer material not suitable for food-contact use may be incorporated into food-contact packaging; 
- the adjuvants from the recycled plastic may not respect the regulations for food-contact use [69].

For example, the reused plastics can be contaminated by pollutants and the pollutants may migrate into the packaged goods in the next life of the material. The following methods are recommended to avoid migration of potential contamination:

- $\quad$ Packaging washing (only if it is used in the same way as before);

- Plastic depolymerization (the monomers are purified efficiently and the produced polymer is as pure as those made from conventional monomers, but this method is expensive);

- Using materials which consist of a few layers; the first layer made from a recycled plastic, the second layer that comes into contact with the product is made from virgin material (act as a functional barrier because it is reducing the migration of the contaminants from the recycled plastic into the packaged food). An example of this method is PET; the removing of all contamination from bottles is expensive, so to obtain a plastic with purity required for products which have direct contact with foods is very hard and for this reason PET is used as the outer layer in multilayered containers with the inner layer (virgin material) acting as a functional barrier [16].

Other important factors in the case of the interactions between packaging plastics and product depend on the sorption properties and on the diffusion behavior which is specific to certain polymer types or individual plastics. So, the inertness of the polymer is the basic parameter which determines the possibility for closed-loop recycling of packaging plastics. It was reported that the polymers which present a better inertness and are more appropriate for being reused in packaging applications are poly (ethylene naphtholate) (PEN), PET, and rigid PVC; followed by PS, HDPE, PP and LDPE which presents much lower properties for this type of application [70].

\subsection{Recycled Polymers for Indoor Applications}

Due to the growth of the number of home electrical appliances from the last years, several environmental risks were associated with these appliances. So, to avoid these risks many countries have introduced recycling systems. For example, the European Union has established three directives on electrical and electronic equipment: 2002/95/EC on restrictions on the use of certain hazardous substances in electrical and electronic equipment; 2002/96/EC on waste electrical and electronic equipment and 2005/32/EC on the eco-design of energy-using products [71].

In recent years, it was observed that electronic waste encompasses a broad and growing range of electronic devices ranging from large household appliances like air conditioners, refrigerators, and consumer electronics for computers and cellular phones. Also, it was reported that the recycling yield has increased since system implementation. The recycling yield rate, the weight of recycled materials divided by the total weight of collected appliances, has gradually increased to more than $70 \%$. For indoor applications, the only used plastics are those in which recycling is from high-grade plastic. For example, polypropylene and polystyrene are recycled and they are used in the back-cabinets of TVs, flow fans, balancers of washing machines, base frames, dewatering tanks and protection nets of air conditioners. Also, polypropylene products are recycled in fresh food cases of refrigerators and water tanks of washing machines [71-75].

\section{Perspectives for a Green Bio-Industry}

The total production of plastics in 2015 was more than 322 million tons/year, which will increase to 400 million tons in 2020; according to PlasticsEurope, in 2015, global plastic's production grew by $3.4 \%$ compared to 2014. The increasing consumption of polymer products in various fields generates a lot of waste materials, which equates to more than $12 \%$ of the urban solid waste stream. Therefore, the world is confronting a crisis, due to the generation of huge amounts of plastic waste by industries and householders; hence, an increasing attempt has been made to cope with waste polymers, due to 
environmental, economic and petroleum concerns. Also, it was reported that 9 countries in Europe reached until 2015 a recovery ratio of more than $95 \%$ of the post-consumer plastic waste because of the landfill ban being well managed. Over the years, it was observed that the recycling process is the best technique to treat waste polymer products, and the old-style methods, such as combustion of waste polymers or burying underground, lead to negative influences on the environment via the formation of dust, fumes and toxic gases or the pollution of underground water and other resources $[65,71,76-78]$. At this moment, the innovations in recycling technologies are represented by detectors and recognition software that collectively increase the accuracy and productivity of automatic sorting such as Fourier Transform Near-Infrared (FT-NIR) detectors which can operate for up to $8000 \mathrm{~h}$ between faults in the detectors [18].

\section{Conclusions}

In summary, thermoplastic polymers are inexpensive, lightweight and durable which make them suitable to be molded into a variety of products that can find use in a wide range of applications. In the last 60 years, the production of plastics has increased significantly causing a big problem in the world. This review aims to provide an updated survey of the main recycled polymers and the recycle methods of thermoplastic polymers. Also, the main applications of thermoplastic polymers based on categorization by the Society of the Plastic Industry (SPI) and the new perspectives with reference to these polymers are presented. This study reveals that the recycling process is the best technique to treat waste polymer products in comparison with the old-style methods (combustion of waste polymers or burying underground) which lead to negative influences on the environment via the formation of dust, fumes and toxic gases.

Conflicts of Interest: The author declares no conflict of interest.

\section{References}

1. Amin, S.; Amin, M. Thermoplastic elastomeric (TPE) materials and their use in outdoor electrical insulation. Rev. Adv. Mater. Sci. 2011, 29, 15-30.

2. Ribeiro, M.C.S.; Fiúza, A.; Ferreira, A.; Dinis, M.D.L.; Meira Castro, A.C.; Meixedo, J.P.; Alvim, M.R. Recycling Approach towards Sustainability Advance of Composite Materials' Industry. Recycling 2016, 1, 178. [CrossRef]

3. Ashori, A. Wood-plastic composites as promising green-composites for automotive industries! Bioresour. Technol. 2008, 99, 4661-4667. [CrossRef] [PubMed]

4. Pascault, J.-P.; Sautereau, H.; Verdu, J.; Williams, R.J. Thermosetting Polymers; CRC Press: Roca Raton, FL, USA, 2002; Volume 64.

5. Brazel, C.S.; Rosen, S.L. Fundamental Principles of Polymeric Materials; John Wiley \& Sons: Hoboken, NJ, USA, 2012.

6. Yang, Y.; Boom, R.; Irion, B.; van Heerden, D.-J.; Kuiper, P.; de Wit, H. Recycling of composite materials. Chem. Eng. Process. Process Intensif. 2012, 51, 53-68. [CrossRef]

7. Schlosser, E.; Nass, B.; Wanzke, W. Flame Retardant Combination for Thermoplastic Polymers L. U.S. Patent 6,547,992, 15 April 2003.

8. Bicerano, J. Prediction of Polymer Properties; CRC Press: Roca Raton, FL, USA, 2002.

9. Ultem, L.; STM, U.S.; Ultrablend, S. Polymer Science Dictionary; Springer: Dordrecht, The Netherlands, 2017; ISBN 978-94-024-0893-5.

10. Nicholson, J. The Chemistry of Polymers; Royal Society of Chemistry: London, UK, 2017.

11. Giboz, J.; Copponnex, T.; Mélé, P. Microinjection molding of thermoplastic polymers: A review. J. Micromech. Microeng. 2007, 17, R96. [CrossRef]

12. Van Krevelen, D.W.; Te Nijenhuis, K. Properties of Polymers: Their Correlation with Chemical Structure; Their Numerical Estimation and Prediction from Additive Group Contributions; Elsevier: Amsterdam, The Netherlands, 2009.

13. Khan, M.I.; Zagho, M.; Shakoor, R. A Brief Overview of Shape Memory Effect in Thermoplastic Polymers. In Smart Polymer Nanocomposites; Springer: Berlin, Germany, 2017; pp. 281-301. 
14. Wei, C.; Esposito, D.; Tauer, K. Thermal properties of thermoplastic polymers: Influence of polymer structure and procedure of radical polymerization. Polym. Degrad. Stab. 2016, 131, 157-168. [CrossRef]

15. Michler, G.H.; Balta-Calleja, F.J. Mechanical Properties of Polymers Based on Nanostructure and Morphology; CRC Press: Roca Raton, FL, USA, 2016; Volume 71.

16. Kolek, Z. Recycled polymers from food packaging in relation to environmental protection. Pol. J. Environ. Stud. 2001, 10, 73-76.

17. Jiun, Y.L.; Tze, C.T.; Moosa, U.; Mou'ad, A.T. Effects of Recycling Cycle on Used Thermoplastic Polymer and Thermoplastic Elastomer Polymer. Polym. Polym. Compos. 2016, 24, 735.

18. Hopewell, J.; Dvorak, R.; Kosior, E. Plastics recycling: Challenges and opportunities. Philos. Trans. R. Soc. Lond. B Biol. Sci. 2009, 364, 2115-2126. [CrossRef] [PubMed]

19. Drobny, J.G. Handbook of Thermoplastic Elastomers; Elsevier: Amsterdam, The Netherlands, 2014.

20. Rodriguez, F.; Cohen, C.; Ober, C.K.; Archer, L. Principles of Polymer Systems; CRC Press: Roca Raton, FL, USA, 2014.

21. Lee, S.-T.; Park, C.B. Foam Extrusion: Principles and Practice; CRC Press: Roca Raton, FL, USA, 2014.

22. Fried, J.R. Polymer Science and Technology; Pearson Education: London, UK, 2014.

23. Myshkin, N.; Pesetskii, S.; Grigoriev, A.Y. Polymer Tribology: Current State and Applications. Tribol. Ind. 2015, 37, 284-290.

24. Park, H.M.; Li, X.; Jin, C.Z.; Park, C.Y.; Cho, W.J.; Ha, C.S. Preparation and properties of biodegradable thermoplastic starch/clay hybrids. Macromol. Mater. Eng. 2002, 287, 553-558. [CrossRef]

25. Koo, J.H. Polymer Nanocomposites: Processing, Characterization, and Applications; McGraw-Hill Professional Pub.: New York, NY, USA, 2006.

26. Schulz, U. Review of modern techniques to generate antireflective properties on thermoplastic polymers. Appl. Opt. 2006, 45, 1608-1618. [CrossRef] [PubMed]

27. Mishra, J.K.; Hwang, K.-J.; Ha, C.-S. Preparation, mechanical and rheological properties of a thermoplastic polyolefin (TPO)/organoclay nanocomposite with reference to the effect of maleic anhydride modified polypropylene as a compatibilizer. Polymer 2005, 46, 1995-2002. [CrossRef]

28. Turi, E. Thermal Characterization of Polymeric Materials; Elsevier: Amsterdam, The Netherlands, 2012.

29. Mano, J.; Koniarova, D.; Reis, R. Thermal properties of thermoplastic starch/synthetic polymer blends with potential biomedical applicability. J. Mater. Sci. Mater. Med. 2003, 14, 127-135. [CrossRef] [PubMed]

30. Wollerdorfer, M.; Bader, H. Influence of natural fibres on the mechanical properties of biodegradable polymers. Ind. Crops Prod. 1998, 8, 105-112. [CrossRef]

31. Nichols, C.; Moore, T.; Griffith, S. Thermoplastic Polymers with Improved Infrared Reheat Properties. U.S. Patent 09/973,436, 9 October 2001.

32. Van de Velde, K.; Kiekens, P. Thermoplastic polymers: Overview of several properties and their consequences in flax fibre reinforced composites. Polym. Test. 2001, 20, 885-893. [CrossRef]

33. Mohammadzadeh, M. Characterization of Recycled Thermoplastic Polymers. Master's Thesis, University of Borås, Borås, Sweden, 2009.

34. Saleh, T.A.; Danmaliki, G.I. Polymer Consumption, Environmental Concerns, Possible Disposal Options, and Recycling for Water Treatment. In Advanced Nanomaterials for Water Engineering, Treatment, and Hydraulics; IGI Global: Hershey, PA, USA, 2017; pp. 200-222.

35. Favis, B.D.; Le Corroller, P. Polymeric material and process for recycling plastic blends. U.S. Patent 9,670,344, 6 July 2017.

36. Francis, R. Recycling of Polymers: Methods, Characterization and Applications; John Wiley \& Sons: Hoboken, NJ, USA, 2016.

37. Singh, N.; Hui, D.; Singh, R.; Ahuja, I.; Feo, L.; Fraternali, F. Recycling of plastic solid waste: A state of art review and future applications. Compos. Part B Eng. 2017, 115, 409-422. [CrossRef]

38. Olah, G.A.; Goeppert, A.; Prakash, G.S. Chemical recycling of carbon dioxide to methanol and dimethyl ether: From greenhouse gas to renewable, environmentally carbon neutral fuels and synthetic hydrocarbons. J. Org. Chem. 2008, 74, 487-498. [CrossRef] [PubMed]

39. Achilias, D.S.; Roupakias, C.; Megalokonomos, P.; Lappas, A.A.; Antonakou, E.V. Chemical recycling of plastic wastes made from polyethylene (LDPE and HDPE) and polypropylene (PP). J. Hazard. Mater. 2007, 149, 536-542. [CrossRef] [PubMed] 
40. Matsumura, S. Enzyme-Catalyzed Synthesis and Chemical Recycling of Polyesters. Macromol. Biosci. 2002, 2, 105-126. [CrossRef]

41. Karayannidis, G.P.; Achilias, D.S. Chemical Recycling of Poly(ethylene terephthalate). Macromol. Mater. Eng. 2007, 292, 128-146. [CrossRef]

42. Karayannidis, G.; Chatziavgoustis, A.; Achilias, D. Poly (ethylene terephthalate) recycling and recovery of pure terephthalic acid by alkaline hydrolysis. Adv. Polym. Technol. 2002, 21, 250-259. [CrossRef]

43. Kumagai, S.; Hirahashi, S.; Grause, G.; Kameda, T.; Toyoda, H.; Yoshioka, T. Alkaline hydrolysis of PVC-coated PET fibers for simultaneous recycling of PET and PVC. J. Mater. Cycles Waste Manag. 2017, 1-11. [CrossRef]

44. Yoshioka, T.; Motoki, T.; Okuwaki, A. Kinetics of hydrolysis of poly (ethylene terephthalate) powder in sulfuric acid by a modified shrinking-core model. Ind. Eng. Chem. Res. 2001, 40, 75-79. [CrossRef]

45. Mehrabzadeh, M.; Shodjaei, S.; Khosravi, M. Chemical recycling of polyethylene terephthalate. Iran. Polym. J. 2000, 9, 37-40.

46. De Carvalho, G.M.; Muniz, E.C.; Rubira, A.F. Hydrolysis of post-consume poly (ethylene terephthalate) with sulfuric acid and product characterization by WAXD, 13 C-NMR and DSC. Polym. Degrad. Stab. 2006, 91, 1326-1332. [CrossRef]

47. Kosmidis, V.A.; Achilias, D.S.; Karayannidis, G.P. Poly (ethylene terephthalate) recycling and recovery of pure terephthalic acid. Kinetics of a phase transfer catalyzed alkaline hydrolysis. Macromol. Mater. Eng. 2001, 286, 640-647. [CrossRef]

48. Colomines, G.; Robin, J.-J.; Tersac, G. Study of the glycolysis of PET by oligoesters. Polymer 2005, 46, 3230-3247. [CrossRef]

49. López-Fonseca, R.; Duque-Ingunza, I.; de Rivas, B.; Flores-Giraldo, L.; Gutiérrez-Ortiz, J.I. Kinetics of catalytic glycolysis of PET wastes with sodium carbonate. Chem. Eng. J. 2011, 168, 312-320. [CrossRef]

50. Yue, Q.F.; Wang, C.X.; Zhang, L.N.; Ni, Y.; Jin, Y.X. Glycolysis of poly(ethylene terephthalate) (PET) using basic ionic liquids as catalysts. Polym. Degrad. Stab. 2011, 96, 399-403. [CrossRef]

51. Wang, H.; Liu, Y.; Li, Z.; Zhang, X.; Zhang, S.; Zhang, Y. Glycolysis of poly(ethylene terephthalate) catalyzed by ionic liquids. Eur. Polym. J. 2009, 45, 1535-1544. [CrossRef]

52. Pardal, F.; Tersac, G. Comparative reactivity of glycols in PET glycolysis. Polym. Degrad. Stab. 2006, 91, 2567-2578. [CrossRef]

53. Yang, Y.; Lu, Y.; Xiang, H.; Xu, Y.; Li, Y. Study on methanolytic depolymerization of PET with supercritical methanol for chemical recycling. Polym. Degrad. Stab. 2002, 75, 185-191. [CrossRef]

54. Achilias, D.S.; Karayannidis, G.P. The Chemical Recycling of PET in the Framework of Sustainable Development. Water Air Soil Pollut. Focus 2004, 4, 385-396. [CrossRef]

55. Kurokawa, H.; Ohshima, M.; Sugiyama, K.; Miura, H. Methanolysis of polyethylene terephthalate (PET) in the presence of aluminium tiisopropoxide catalyst to form dimethyl terephthalate and ethylene glycol. Polym. Degrad. Stab. 2003, 79, 529-533. [CrossRef]

56. Rahimi, A.; García, J.M. Chemical recycling of waste plastics for new materials production. Nat. Rev. Chem. 2017, 1. [CrossRef]

57. Achilias, D.; Antonakou, E.; Roupakias, C.; Megalokonomos, P.; Lappas, A. Recycling techniques of polyolefins from plastic wastes. Glob. NEST J. 2008, 10, 114-122.

58. Ke, H.; Li-Hua, T.; Zi-Bin, Z.; Cheng-fang, Z. Reaction mechanism of styrene monomer recovery from waste polystyrene by supercritical solvents. Polym. Degrad. Stab. 2005, 89, 312-316. [CrossRef]

59. Al-Salem, S.; Lettieri, P.; Baeyens, J. Recycling and recovery routes of plastic solid waste (PSW): A review. Waste Manag. 2009, 29, 2625-2643. [CrossRef] [PubMed]

60. Fisher, M.M.; Mark, F.E.; Kingsbury, T.; Vehlow, J.; Yamawaki, T. Energy Recovery in the Sustainable Recycling of Plastics from End-of-Life Electrical and Electronic Products. In Proceedings of the 2005 IEEE International Symposium on Electronics and the Environment, New Orleans, LA, USA, 16-19 May 2005; pp. 83-92.

61. Andrady, A.L. Plastics and the Environment; John Wiley \& Sons: Hoboken, NJ, USA, 2003.

62. Ragaert, K.; Delva, L.; Van Geem, K. Mechanical and chemical recycling of solid plastic waste. Waste Manag. 2017, 69, 24-58. [CrossRef] [PubMed]

63. European Association of Plastics Recycling and Recovery. Available online: http://www.eproplasticsrecycling.org/pages/75/epro_statistics (accessed on 24 June 2017). 
64. Siddique, R.; Khatib, J.; Kaur, I. Use of recycled plastic in concrete: A review. Waste Manag. 2008, 28, 1835-1852. [CrossRef] [PubMed]

65. Zare, Y. 3Recycled Polymers: Properties and Applications. Available online: https://www.smithersrapra.com/ SmithersRapra/media/Sample-Chapters/Recycled-Polymers-Properties-and-Applications,-Volume-2.pdf (accessed on 28 November 2017).

66. Gallop, W.A.; Evans, M.G.; Mithal, A.K. Knife Having Superior Functionality and Appeal. U.S. Patent 12/455,322, 3 December 2009.

67. Achilias, D.; Giannoulis, A.; Papageorgiou, G. Recycling of polymers from plastic packaging materials using the dissolution-reprecipitation technique. Polym. Bull. 2009, 63, 449-465. [CrossRef]

68. Plastic Coding Guidelines in the United States. Available online: http://www.natureworksllc.com/ / media/The_Ingeo_Journey/EndofLife_Options / plastic_codes/2008_04_10_plastic_code_guidelines_pdf.pdf (accessed on 6 November 2017).

69. Recycled Plastics in Food Packaging. Available online: https://www.fda.gov/food/ ingredientspackaginglabeling/packagingfcs/recycledplastics/default.htm (accessed on 25 June 2017).

70. Franz, R.; Welle, F. 23-Recycling packaging materials A2-Ahvenainen, Raija. In Novel Food Packaging Techniques; Woodhead Publishing: Cambridge, UK; 2003; pp. 497-518.

71. Aizawa, H.; Yoshida, H.; Sakai, S.-I. Current results and future perspectives for Japanese recycling of home electrical appliances. Resour. Conserv. Recycl. 2008, 52, 1399-1410. [CrossRef]

72. Shih, L.-H. Reverse logistics system planning for recycling electrical appliances and computers in Taiwan. Resour. Conserv. Recycl. 2001, 32, 55-72. [CrossRef]

73. Park, C.-H.; Jeon, H.-S.; Yu, H.-S.; Han, O.-H.; Park, J.-K. Application of Electrostatic Separation to the Recycling of Plastic Wastes: Separation of PVC, PET, and ABS. Environ. Sci. Technol. 2008, 42, 249-255. [CrossRef] [PubMed]

74. Li, J.; Lu, H.; Guo, J.; Xu, Z.; Zhou, Y. Recycle technology for recovering resources and products from waste printed circuit boards. Environ. Sci. Technol. 2007, 41, 1995-2000. [CrossRef] [PubMed]

75. Bianchini, F.; Hewage, K. How "green" are the green roofs? Lifecycle analysis of green roof materials. Build. Environ. 2012, 48, 57-65. [CrossRef]

76. PlasticsEurope. Available online: https://committee.iso.org/files/live/sites/tc61/files/The\%20Plastic\% 20Industry\%20Berlin\%20Aug\%202016\%20-\%20Copy.pdf (accessed on 21 July 2017).

77. Rudolph, N.; Kiesel, R.; Aumnate, C. Understanding Plastics Recycling: Economic, Ecological, and Technical Aspects of Plastic Waste Handling; Carl Hanser Verlag GmbH Co. KG: Munich, Germany, 2017.

78. Bates, M.P. Plastics Recycling: The Big Challenges, the Big Opportunities UK and International. Presented at Recoup Annual Conference, Peterborough, UK, 29 September 2016. 